\title{
Rating Procedure for Mixed Air Source Unitary Air Conditioners and Heat Pumps Operating in the Cooling Mode
}

Piotr A. Domanski

U.S. DEPARTMENT OF COMMERCE

National Bureau of Standards National Engineering Laboratory Center for Building Technology Building Equipment Division Gaithersburg, MD 20899

February 1986

Sponsored by:

- partment of Energy

100 gton, DC 20585

.456

$86-3301$

1986 



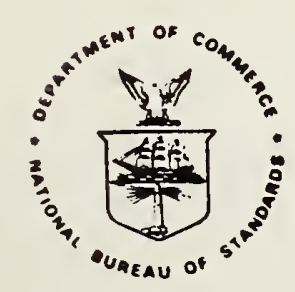



RATING PROCEDURE FOR MIXED AIR SOURCE UNITARY AIR CONDITIONERS AND HEAT PUMPS OPERATING IN THE COOLING MODE

\section{Abstract}

A procedure is presented for rating split, residential air conditioners and heat pumps operating in the cooling mode which are made up of an evaporator unit combined with a condensing unit which has been rated under current procedures in conjunction with a different evaporator unit. The procedure a 110 s calculation of capacity at the $95^{\circ} \mathrm{F}$ rating point and seasonal energy efficiency ratio, SEER, without performing laboratory tests of the complete system. This procedure has been prepared for the Department of Energy for consideration in the rule making process.

Key Words: Air conditioner, central air conditioner, heat pump, mixed system, mixed-matched system, rating procedure 
1. PURPOSE ............................ 1

2. $\mathrm{SCOPE} \ldots \ldots \ldots \ldots$

3. DEF INITIONS . . . . . . . . . . . . . . . 1

4. PROCEDURE FOR RATING UIXED SYSTEM . . . . . . . . . . 3

4.1 Rating Correlations ............... 3

4.2 Indoor Coll Scaling Factor ............. 5

4.2.1 Determination of the Indoor Coll Scaling Factor... 5

4.2 .2 Restrictions . . . . . . . . . . . . 6

4.2.3 Verification of Coil Capacity Determination Method . 6

4.3 Expansion Devico Scaling Factor . . . . . . . . 8

4.3.1 Determination of the Expansion Device Scaling Factor . 8

4.3.2 Restrictions . . . . . . . . . . . . . 8

4.3.3 Equations for Calculating Expansion Device Scaling Factor ................ 11

4.4 Power Input to the Indoor Fan . . . . . . . . . 13

4.4.1 Power Inpat to the Indoor Fan of the Matched System. 13

4.4.2 Power Input to the Indoor Fan of the Mixed System . . 14

4.5 Values of Ratings . . . . . . . . . . . . 14

4.5.1 Values of Capacity at Test A ........... 14

4.5.2 Values of Seasonal Energy Efficiency Ratio, SEER ... 15

5. ALTERNATIVE RATING PROCEDURE FOR MIXED SYSTEMS . . . . . 15

6. REFERENCES ....................... 16 


\section{PURPOSE}

The purpose of this report is to establish procedures for determining the cooling performance ratings of air source unitary air-conditioners and heat pumps consisting of a condensing unit and an evaporator which were not tested together as a system. The performance ratings covered in this document are the cooling capacity at Test A conditions and seasonal energy efficiency ratio, SEER, defined by ARI Standard 210/240-84 [1]. This rating methodology is a composite of independent measurements and calculations made on an outdoor unit in conjunction with a matched indoor coil, and a mixed indoor coil.

\section{SCOPE}

This procedure applies to residential air-conditioning and heat pump systems charged with Refrigerant 22 consisting of an indoor air-cooling coil assembly and an outdoor single-phase, electric, air source unit whose matched system* cooling capacity** is less than $65,000 \mathrm{Bta} / \mathrm{h}(19,050.0 \mathrm{~W})$. This procedure does not apply to systems employing multispeed compressors, or systems in which compressor control strategy changes with load (e.g., cylinder unloads, hot-gas bypass). Additional limitations as to the quantitative range of the scope of this document are given in Sections 4.2 .2 and 4.3.2.

\section{DEFINITIONS}

All definitions included in or cited by ARI Standard 210/240-84 [1] sha11 be considered part of this procedure in addition to the following definttions. 
3.1 ARI - Air Conditioning and Refrigeration Institute.

3.2 Alr Source Onitary Air Conditioner or Air Source Unitary Heat Pump or Unitary System - an outdoor unit combined with an indoor coll asembly.

3.3 Ontdoor Dnit - an assembly of refrigerating components designed to compress and liquify a specific refrigerant. It consists of refrigerant vapor compressor, air-cooled refrigerant coil, coil fan and motor, and regularly furnished accessories. A liquid line solenoid valve and other cyclic performance enhancing devices (excluding the expansion device itself), if included in an air-conditioner or heat pump, are considered to be a part of the outdoor unit.

3.4 Indoor Coil Assemb1y - an assemb1y consisting of a coil, condensate collecting pan, and expansion device, and which may or may not include a blower, motor and cabinet.

3.5 Matched Coil - an indoor coil which is a part of the matched system.

3.6 Matched System - a unitary system which has been tested and noted in accordance with ARI Standard 210/240-84 [1] and Part 430.23 of Title 10, Code of Federal Regulations [2].

3.7 Mixed Coil - an indoor coil which is used in a unitary system instoad of the matched ooil. 
3.8 Mixed System - a unitary system which is not a matched system.

3.9 Shall - where 'sha11' or 'shall not' are used for a provision specified, that provision is mandatory if compliance with the standard is claimed.

3.10 Should, Recommended, or It Is Recommended - 'should', 'recommended', or 'it is recommended' are used to indicate provisions which are not mandatory but which are desirable as good practice.

4. PROCEDURE FOR RATING MIXED SYSTEM

\subsection{Rating Correlations}

Mired system capacity at DoE Test A condition, $Q_{X}$, shall be calculated using

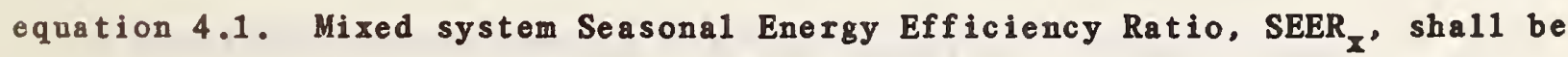
calculated using equations $4.2,4.3$, and 4.4 (derivation of these equations will be presented in a separate publication).

$$
\begin{aligned}
& Q_{x}=\left[Q_{m}+3.413 \cdot P_{F, m}\right] \cdot F_{c}^{0.37} \cdot F_{e}^{Q}-3.413 \cdot P_{F, x} \\
& \operatorname{SEER}_{\mathrm{x}}=\operatorname{SEER}_{\mathrm{m}}\left(\frac{Q_{\mathrm{I}}}{Q_{\mathrm{m}}}\right)_{82} \cdot\left(\frac{P_{\mathrm{I}}}{\mathrm{P}_{\mathrm{m}}}\right)_{82}^{-1} \cdot \mathrm{F}_{\mathrm{TXV}}
\end{aligned}
$$

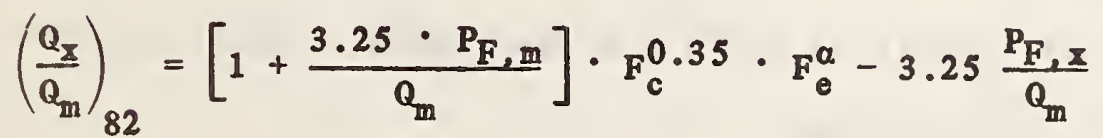

$$
\begin{aligned}
& \left(\frac{P_{I}}{P_{m}}\right)_{82}=0.8 \cdot F_{c}^{0.14} \cdot F_{Q}^{\beta}+0.1 \frac{P_{F, I}}{P_{F, m}}+0.1
\end{aligned}
$$

Symbols used in equations $4.1,4.2,4.3$ and 4.4 are explained below. 


\section{Exponents}

$$
\begin{aligned}
& \alpha=-0.15 \text { for } F_{e} \geq 1 \\
& \alpha=0 \text { for } F_{e}<1 \\
& \beta=0 \text { for } F_{e} \geq 1 \\
& \beta=-0.2 \text { for } F_{e}<1
\end{aligned}
$$

\section{Other Symbo1s}

$F_{c}=$ indoor coil scaling factor calculated as explained in section 4.2 .1 .

$\mathrm{F}_{\theta}=$ expansion device scaling factor calculated as explained in section 4.3 .1 .

$F_{\text {TXV }}=$ thermostatic expansion valve factor. (Shall be evaluated as shown in Tab1e 1).

$P_{F, m}=$ power input to the indoor fan of a matched system as defined in Section 4.4.1 (wat $t)$.

$P_{F, x}=$ power input to the indoor fan of the mixed system as defined in Section 4.4 .2 (wat $t$ ).

$Q_{m}=$ capacity of the matched system at Test $A$ as certified by its manufacturer $(B t u / h)$.

$Q_{\Sigma}=$ capacity of a mirod system at Test $A$, as calculated by equation $4.1(B t u / h)$. $\left(\frac{Q_{2}}{Q_{m}}\right)_{82}=$ ratio of capacities at Test B conditions of the mixed and

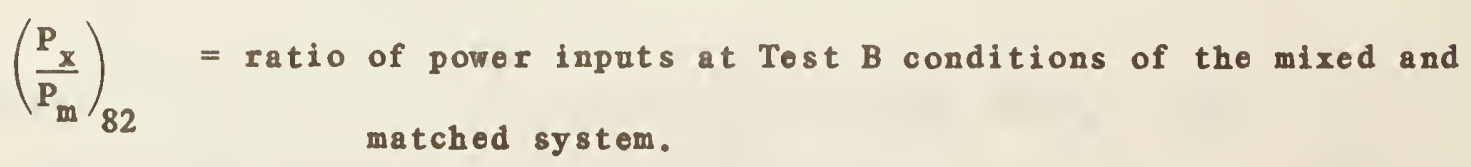

SEER $_{m}$ = seasonal energy officienoy ratio of the matched system

(Btu/h - watt) as certified by its manufacturer. 


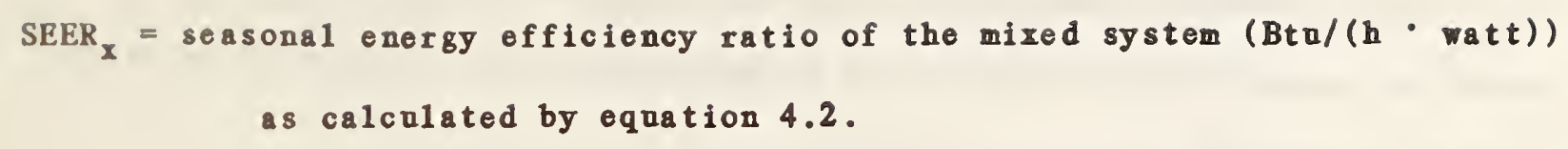

\subsection{Indoor Coil Scaling Factor}

4.2.1 Determination of the Indoor Coil Scaling Factor

The indoor coil scaling factor, $F_{c}$, is defined by the following equation:

$$
F_{c}=\frac{Q_{c, I}}{Q_{c, m}}
$$

where:

$Q_{c, I}=$ cooling capacity of a mized coil at the air mass flow rate specified for the mixed system. The air mass flow rate specified for the mixed system shall satisfy conditions of section 5.1.3.3, ARI Standard 210/240-84.

$Q_{c, m}=$ cooling capacity of a matched coil at the indoor-air volumetric flow rate, $\mathrm{CFM}_{\mathrm{m}}\left(\mathrm{ft}^{3} / \mathrm{min}\right)$, at which matched system capacity, $Q_{m}$, was measured. If CFM information is not available, the value for the indoor air volumetric flow rate shall be calculated as follows:

$$
\mathrm{CFM}_{\mathrm{m}}=\frac{Q_{\mathrm{m}}}{12000} \cdot 425\left(\mathrm{ft}^{3} / \mathrm{min}\right)
$$

Capacities of matched and mixed coils shall be obtained using the same verified method (see Section 4.2 .3 ). Coil capacities shall be obtainod at the following conditions: 
- Inlet air conaitions - $80^{\circ} \mathrm{F}$ dry bulb/670F wet bulb

- refrigerant saturation temperature at the evaporator outlet $45^{\circ} \mathrm{F}$

- identical refrigerant superheat at the evaporator outlet

If coil capacitios are obtained by means of a catalog or computer simulation, the same catalog or computer simulation shall be used for both coils. Coil material and goometry $(0.8 .$. inside tube diameter, tube staggering, fin spacing, fin thickness, fin shape, and number of tube depth rows) shall be accounted for by the method used. That is, the methodology used must have these parameters as independent variables.

\subsubsection{Restrictions}

The acceptable range of values for the indoor coil scaling factor, $F_{c}$, is from 0.8 to 1.3. This rating procedure shall not be used if the indoor coil scaling factor is smaller than 0.8 . If the ratio $Q_{c, x} / Q_{c, m}$ results in a value greater than 1.3, the value of the indoor coil scaling factor, $F_{c}$ shall be 1.3 .

\subsubsection{Verification of Coil Capacity Determination Method}

A variety of methodologies exist for calculating the capacity of a coll based on material and geometry data only. For example, several large heat exchanger manufacturing companies publish catalogues of performance curves for their specific products which are commonly used in a generic fashion. That is, the capacity of coils of the same materials and of the same number of rows, tube patterns and diameters, fin spacing, shape, and thicknoss is assumed to bo the 
same for all manufacturers. Similarily there exist many computer simulations which are based either on regression analysis of the above mentioned catalogue data or on first principles of the heat transfer phenomena involved. If a specific methodology of either of these categories has at least the independent variables 1 isted above, it may be used in this procedure to predict the capacities of the coils (i.e., $Q_{c, x}$ and $Q_{c, m}$ ). However, the specific methodology chosen must be verified by test, in accordance with ASHRAE Standard 3378 [3] and ARI Standard 410-81 [4], to demonstrate that it is sufficiently accurate to simulate the coil line which is being used in the mized system rating.

This verification requires that, for a given coil 1 ine, the capacity range over which the methodology is being used to predict values must be straddled by at least two tests which are within $5 \%$ agreement with the predictions. For example; if a manufacturer produces a line of coils with six sizes having capacities ranging from $20000 \mathrm{Bta} / \mathrm{h}$ to $33000 \mathrm{Btu} / \mathrm{h}$ and uses a single methodology (e.g., computer simulation) to predict the sir individual capacity values, the methodology must be within 5\% agreement with the test values of a coil from that line which is $\leq 20000 \mathrm{Bta} / \mathrm{h}$ and $\geq 33000 \mathrm{Bta} / \mathrm{h}$. A similar pair of tests stradding the matched coil is also required if the methodology has not been previously verified for that 1 ine.

A coil line is defined as a group of coils which are of the same materials and bonding procedure, configuration (i.e., flat or A-shape), row staggering, fin thickness, fin spacing, fin shape (i.e., flat, wavy, corrugated odge, etc.). tube diameters and internal surface finish. If any of these parameters differ then a new coil line has been defined and a new verification test pair is 
required for the methodology.

It is recognized that different numbers of tube rows and circuitry are not being considered as defining a new coll line; yet they probably have a significant effect on performance, all other parameters being held constant. However the state of the art of coil performance simulation or representation is such that these variables are seldom considered. Some first principle computer simulation programs, such as the one used to develop this standard. do exist but they are not widely available and are usually so complex that inpt errors are easily possible. It therefore appears anreasonable to require this degree of sophistication for coil rating at this time.

\subsection{Expansion Device Scaling Factor}

\subsubsection{Determination of the Expansion Device Scaling Factor}

The expansion device scaling factor, $F_{e}$, depends on the types of matched and mized expansion devices involved. It shall be a determined using Table 1 which provides a value for the scaling factor or refers to an equation by which the scaling factor shall be calculated.

\subsubsection{Restrictions}

This rating procedure shall not be used if:

a) the expansion device scaling factor, Fe calculated by the recommended equation is less than 0.85 , or greater than 1.35 .

b) the matched system employs a thermostatic expansion valve and the mized system employs a capillary tube or an orifice. 
c) the mixed expansion device consists of capillary tubes or orifices connected in series.

d) the matched expansion device consists of capillary tubes or orifices connected in series unless the mized expansion device is a thermostatic expansion device. 
Table 1. Evaluation of the Expansion Device Scaling Factor, Fe, and the Thermostatic Expansion Value Factor, FrVV.

\begin{tabular}{|c|c|c|c|}
\hline Matched System & Mixed System & & \\
\hline TXV, no bleed & TXV, no bleed* & 1.0 & 1.000 \\
\hline TXV, no bleed & TXV, w/b1eed* & 1.0 & 0.975 \\
\hline TXV, w/bleed & TXV, no bleed* & 1.0 & 1.025 \\
\hline TXV, w/b1eed & TXV, w/b1eed* & 1.0 & 1.000 \\
\hline $\begin{array}{l}\text { Capil1ary } \\
\text { or } \\
\text { Orifice }\end{array}$ & TXV, no bleed** & 1.0 & 1.050 \\
\hline $\begin{array}{l}\text { Capi11ary } \\
\quad \text { or } \\
\text { Orifice }\end{array}$ & TXV, w/b1eed** & 1.0 & 1.025 \\
\hline Capil1ary & Capi11ary & eq. 4.7 & 1.000 \\
\hline Capillary & Orifice & eq. 4.8 & 1.000 \\
\hline Orifice & Capil1ary & eq. 4.9 & 1.000 \\
\hline Orifice & Orifice & eq. 4.10 & 1.000 \\
\hline
\end{tabular}

*the mixed TXV shall have equivalent capacity and same superheat setting as the matched TXV.

* the mired TXV sha11 have equivalent capacity as the matched expansion device 
4.3.3 Equations for Calculating Expansion Device Scaling Factor

The expansion device scaling factor, $F_{e}$, is the ratio of refrigerant mass flow rates through the mixed and matched expansion devices at the same operating conditions.

This section provides equations for calculating the expansion device scaling

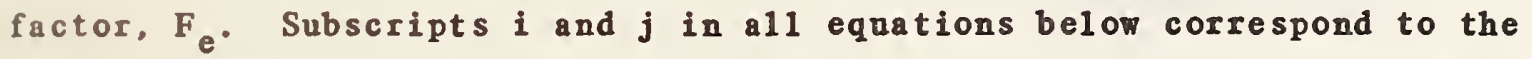
number of parallelly connected capillary tubes or orifices in the mixed and matched expansion devices, respectively. Symbol D denotes the inner diameter (inch) and symbol L denotes the length (inch) of a capillary tube or an orifice. Subscripts $x$ and m refer to mized and matched expansion devices, respectively. If inner diameter or length is required in the recommended equation, it should be measured by methods providing precision of $\pm 1.5 \%$.

If a matched expansion device and a mixed expansion device consist of capillary tubes, the following equation shall be used:

$$
F_{e}=\frac{\sum \Phi_{x, i}}{\sum \Phi_{m, j}}=\frac{\Phi_{x, 1}+\Phi_{x, 2}+\ldots \Phi_{z, i}}{\Phi_{m, 1}+\Phi_{m, 2}+\ldots \Phi_{m, j}}
$$

where $\Phi_{X}$ and $\Phi_{m}$ are flow factors for capillary tubes employed in the mixed and matched expansion devices, respectively, determined based on their geometry with the aid of the ASHRAE Handbook, Equipment Volume, 1983, Chapter 20, Figure $38[5]$.

If a matched expansion device consists of capillary tubes and a mixed expansion device consists of orifices the following equation should be used: 


$$
F_{\theta}=\frac{\sum \Phi_{z, 1}}{109.6 \cdot \sum \Phi_{m, j}}=\frac{\Phi_{z, 1}+\Phi_{z, 2}+\ldots+\Phi_{z, 1}}{109.6\left(\Phi_{m, 1}+\Phi_{m, 2}+\ldots \Phi_{m, j}\right)}
$$

Whore

$$
\begin{aligned}
& \Phi_{X}=\frac{72200 D^{2}}{\left(0.58+0.008 \frac{L_{z}}{D_{z}}{ }^{0.5}\right.} \\
& \Phi_{m}=\text { flow factor for a capillary tabe employed in a matched expansion } \\
& \text { device, and determined based on geometry with the aid of ASHRAE } \\
& \text { Handbook, Equipment Vo1ume, 1983, Chapter 20, Figure } 38 \text { [5]. }
\end{aligned}
$$

If a matched expansion device consists of orifices and a mixed expansion device consists of capillary tubes the following oquation should be used:

$$
F_{e}=\frac{109.6 \cdot \sum \Phi_{x, i}}{\sum \Phi_{m, j}}=\frac{109.6\left(\Phi_{x, 1}+\Phi_{x, 2}+\ldots+\Phi_{x, i}\right)}{\Phi_{m, 1}+\Phi_{m, 2}+\ldots+\Phi_{m, j}}
$$

where

$\Phi_{x}=$ flow factor for a capillary tubo employed in a mixed expansion device, and determined based on geometry with the aid of ASHRAE Handbook, Equipment Volume, 1983, Chapter 20, Fig. 38 [5].

$$
\Phi_{\text {m }}=\frac{72200 D_{m}^{2}}{\left(0.58+0.008 \frac{L_{m}}{D_{m}}\right)^{0.5}}
$$


If a matched expansion device consists of orifices and a mixed expansion device consists of orifices the following equation should be used:

$$
F_{e}=\frac{\sum \Phi_{x, 1}}{\sum \Phi_{m, j}}=\frac{\Phi_{x, 1}+\Phi_{x, 2}+\ldots \Phi_{x, i}}{\Phi_{m, 1}+\Phi_{m, 2}+\ldots \Phi_{m, j}}
$$

where

$$
\begin{aligned}
& \Phi_{x}=\frac{D_{x}^{2}}{\left(0.58+0.008 \frac{L_{x}}{D_{x}}\right)^{0.5}} \\
& \Phi_{m}=\frac{D_{m}^{2}}{\left(0.58+0.008 \frac{L_{m}}{D_{m}}\right)^{0.5}}
\end{aligned}
$$

\subsection{Power Input to the Indoor Fan}

\subsubsection{Power Input to the Indoor Fan of the Matched System}

Power input to the indoor fan, $P_{F, m}$ shall be measured in accordance with the ARI Standard 210/240-84 [1] at the indoor-air volumetric flow rate, CFM, at which capacity of the matched system, $Q_{m}$, was measured. If CFM information is not available, the value for the indoor-air volumetric flow rate shall be calculated by equation (4.6). If the indoor fan is not supplied with the system, $P_{F, m}$ shall be evaluated by the equation:

$$
P_{F, m}=0.365 \cdot \text { CFM }_{m}
$$

where CFM $\left(\mathrm{ft}^{3} / \mathrm{min}\right)$ is a volumetric flow of air through the matched indoor coil at which system capacity, $Q_{m}$, was measured. 


\subsubsection{Power Input to the Indoor Fan of the Mixed System}

Power input to the indoor fan, $P_{F}, z$ shall be measured in accordance with the ARI Standard 210/240-84 [1] at tho Indoor volumetrio ix flow rate, CFu, at which capacity of the mixed systom, $Q_{x}$, is evaluated. If the indoor fan is not supplied with the system. $P_{\mathrm{F}, x}$ shall be evaluated by the equation:

$$
\mathrm{P}_{\mathrm{F}, \mathrm{x}}=0.365 \cdot \mathrm{CFM}_{\mathrm{x}}
$$

where CFM $\left(\mathrm{ft}^{3} / \mathrm{min}\right)$ is the volumetric flow of air through the mixed indoor coil at which the capacity of the mixed system, $Q_{X}$, is to be evaluated.

\subsection{Values of Ratings}

4.5.1 Values of Capacity at Test A

The capacity at Test A shall be expressod in of Bto/h (W) in multiples of :

\section{Capacities}

$\underline{B t u / h}$ (W)

Less than 20,000 (1ess than 5,900)

20,000 up to $38,000(5,900$ up to 11,000$)$

38,000 up to $65,000(11,100$ up to 19,000$)$ s00 (150)

65,000 and above $(19,000$ and above $)$

\section{Mu1tiples}

$\underline{B t u} / \mathrm{h}(\mathbb{T})$

$100(30)$

$200(60)$

$1,000(300)$

The capacity value shall not exceed $Q_{x}$ value as calculated by equation (4.1). 
4.5.2 Values of Seasonal Energy Efficiency Ratio, SEER

The Seasonal Energy Efficiency Ratio, SEER, shall be expressed in multiples of 0.05 . The Seasonal Energy Efficiency Ratio sha11 not exceed SEER as calculated by equation (4.2).

5. ALTERNATIVE RATING PROCEDURE FOR MIXED SYSTEMS

The large number of variables and the complexities of their interactions associated with an air conditioner always make theoretical or quasi-empirical rating procedures less certain than a whole system test. Therefore, an acceptable alternative to this entire methodology is a formal certification program in which a significant number of the mixed systems created by the use of a single coil line is measured. At this time, the ARI Unitary Certification Program for Coil Manufacturers is the only known program with the objectivity and technical sophistication to be accepted in 1 ied of this rating procedure. However, other test programs may develop in the future and they should be submitted for consideration. 


\section{REFERENCES}

1. Air-Conditioning and Refrigeration Institute, Standard 210/240-84, Standard for Unitary Air-Conditioning and Air Source Heat Pump Equipment, Arlington, Virginia, 1984.

2. Code of Federal Regulations, Title 10, Part 430.23, Washington, D.C., 1985.

3. American Society of Heating, Refrigerating, and Air-Conditioning Engineers, Inc., Standard 33-78, Method of Testing Forced Circulation AirCooling and Air-Heating Coils, New York, NY 1978.

4. Air-Conditioning and Refrigeration Institute, Standard 410-81, Standard for Forced-Circulation Air-Cooling and Air-Heating Coils, Arlington, Virginia, 1981 .

5. American Society of Heating, Refrigeration, and Air-Conditioning Engineers, Inc., ASHRAE Handbook, Equipment Volume, Chapter 20, Fig. 38 , Atlanta, GA, 1983 . 


\begin{tabular}{|c|c|c|c|}
\hline $\begin{array}{l}\text { U.s. DEPT. OF COMM. } \\
\text { BIBLIOGRAPHIC DATA } \\
\text { SHEET (See instructions) }\end{array}$ & $\begin{array}{l}\text { 1. PUBLICATION OR } \\
\text { REPORT NO. } \\
86-3301\end{array}$ & 2. Performing Organ. Report No. & $\begin{array}{l}\text { 3. Publication Date } \\
\text { FEBRUARY } 1986\end{array}$ \\
\hline \multicolumn{4}{|c|}{$\begin{array}{l}\text { Rating Procedure for Mixed Air Source Unitary Air Conditioners and Heat Pumps } \\
\text { Operating in the Cooling Mode }\end{array}$} \\
\hline \multicolumn{4}{|l|}{$\begin{array}{l}\text { 5. AUTHOR(S) } \\
\text { Domanski, P.A. }\end{array}$} \\
\hline \multicolumn{3}{|c|}{$\begin{array}{l}\text { 6. PERFORMING ORGANIZATION (If joint or other than NBS, see instructions) } \\
\text { NATIONAL BUREAU OF STANDARDS } \\
\text { DEPARTMENT OF COMMERCE } \\
\text { WASHINGTON, D.C. } 20234\end{array}$} & $\begin{array}{l}\text { 7. Contract/Grant No. } \\
\text { 8. Type of Report \& Period Covered }\end{array}$ \\
\hline \multicolumn{4}{|c|}{$\begin{array}{l}\text { 9. SPONSORING ORGANIZATION NAME AND COMPLETE ADDRESS (Street, City. Stote, ZIP) } \\
\text { U.S. Department of Energy } \\
\text { Washington, D.C. } 20585\end{array}$} \\
\hline
\end{tabular}

10. SUPPLEMENTARY NOTES

Document describes a computer program; SF-185, FIPS Software Summary, is attached.

11. ABSTRACT (A 200-word or less factual summary of most significant information. If document includes a significant bibliography or literature survey, mention it here)

A procedure is presented for rating split, residential air conditioners and heat pumps operating in the cooling mode which are made up of an evaporator unit combined with a condensing unit which has been rated under current procedures in conjunction with a different evaporator unit. The procedure allows calculation of capacity at the $95^{\circ} \mathrm{F}$ rating point and seasonal energy efficiency ratio, SEER, without performing laboratory tests of the complete system. This procedure has been prepared for the Department of Energy for consideration in the rule making process.

12. KEY WORDS (Six to twelve entries; olphabetical order: copitalize only proper names; ond separate key words by semicolons) air conditioner; central air conditioner; heat pump; mixed system; mixed-matched system; rating procedure

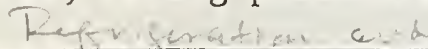

\section{AVAILABILITY}

X] Unlimited

For Official Distribution. Do Not Release to NTIS

Order From Superintendent of Documents, U.S. Government Printing Office, Washington, D.C. 20402.

X] Order From National Technical Information Service (NTIS), Springfield, VA, 22161

14. NO. OF PRINTED PAGES 21

15. Price 

